\title{
Jeito de mulher rural: a busca de direitos sociais e da igualdade de gênero no Rio Grande do Sul*
}

ALIE VAN DER SCHAAF**

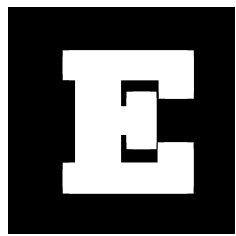

ste trabalho trata de processos emancipatórios de mulheres, em especial de agricultoras no sul do Brasil, no Movimento de Mulheres Trabalhadoras Rurais do Rio Grande do Sul - MMTR-RS. É um movimento em que as mulheres tiveram uma participação massiva, procurando modificar a imagem tradicional da mulher agricultora desrespeitada, negligenciada, invisível e sem voz, em combinação com sua escassa participação na política partidária. A mobilização das agricultoras na região do Planalto no Rio Grande do Sul ocorreu na década de 1980, período que se caracterizou por uma efervescência de mobilização social em todo o Brasil, a partir da abertura política. As mulheres tiveram um papel de destaque nessa mobilização, através de vários tipos de organização, articulados pelo movimento feminista, pela Igreja e sindicatos.

Através da formação do movimento MMTR-RS, a categoria das trabalhadoras rurais obteve representação política e ganhou visibilidade na arena pública. O jeito como as agricultoras deram expressão e forma à sua "luta" surgiu de um processo complexo entre significados culturais da ca-

* Este artigo foi apresentado no "Tercer Congreso Internacional" de Latinoamericanistas na Europa. Amsterdam, 3-6 de julho 2002.

**Pesquisadora no Fryske Akademy, Holanda. 
tegoria e limites impostos pelo sistema político. Neste artigo, pretendo analisar como esse processo teve lugar no MMTR-RS, tomando por base dados obtidos numa pesquisa elaborada em 1996-1997. ${ }^{1}$ A interseção entre a vida diária e a participação no movimento era central nessa pesquisa, bem como o processo de formação do movimento, no qual a Igreja Católica desempenhou um papel crucial.

\section{MMTR-RS}

O MMTR-RS foi fundado em 1989, quando, no Rio Grande do Sul, três grupos regionais ${ }^{2}$ das Mulheres da Roça, ativas desde 1986, transformaram-se num movimento estadual e autônomo de agricultoras e para as agricultoras, com vistas à sua participação. A organização estava nas mãos de mulheres rurais e tinha como objetivo a sua emancipação. A estrutura baseava-se nos princípios da participação direta, da vida cotidiana e do pragmatismo das agricultoras rurais. Foi criada uma estrutura que o movimento chama de democrática. A inovação principal do movimento foi o estabelecimento da igualdade social e política na vida das agricultoras para que pudessem realizar a sua emancipação através da conscientização adquirida pelo convívio com o conjunto das outras mulheres. Com a aspiração de ser uma organização igualitária, antiautoritária e democrática, que aposta nas mudanças nos valores e estilos de vida, na vida política e social, no que se refere às pequenas agricultoras, o movimento apresenta grande semelhança com os surgidos no período da abertura política, os chamados "novos movimentos sociais".

1 A pesquisa foi de caráter qualitativo, sendo seu objetivo a obtenção do título de doutoramento na Antropologia Cultural. Foram utilizados os métodos de observação participativa, entrevistas formais e informais e um pequeno questionário. Objeto de pesquisa foram as (ex-)participantes no movimento e os intermediários. A pesquisa concentrou-se nos municípios de Sananduva (Alto da Serra), Marcelino Ramos (Alto Uruguai) e Ronda Alta (Planalto).

2 Os grupos regionais de Mulheres da Roça eram ligadas à oposição sindical e à lgreja e tinham assim a mesma delimitação geográfica. Formaram-se grupos em Alto Uruguai, Alto da Serra e Planalto. A denominação de 'regional' também expressa a origem local do movimento das mulheres em oposição às regulações 'de cima', do Estado. 
Todas as participantes do movimento nos grupos de base são mulheres agricultoras que moram e trabalham numa roça, um pequeno estabelecimento agrícola de até 20 ha. Algumas participantes têm a propriedade do estabelecimento, outras o arrendam e outras são assentadas ou mulheres sem-terra. A categoria legal dos trabalhadores rurais foi criada com o Estatuto da Terra em 1964. Para as lideranças do movimento, o nome expressa o status e reconhecimento profissional, sendo agricultoras incluídas na categoria de trabalhadores rurais.

\section{A mobilização feminina}

As bases do movimento foram fundadas no período da abertura política, quando o conjunto das organizações de mulheres no Brasil reivindicou vez e voz nas decisões políticas. As feministas tiveram um papel de liderança na articulação política das demandas femininas, enquanto a Igreja Popular ${ }^{3}$ organizou "o povo". A Igreja Popular, incentivada pelos altos escalões da Igreja, ofereceu a inspiração religiosa e estrutura física para entender e interpretar a turbulência das mudanças sociais, econômicas e políticas (por que passava o país). No campo, o feminismo não encontrou ressonância, ao passo que, com as premissas da Teologia de Libertação, a Igreja Popular mobilizou um grande contingente de pequenos agricultores no contexto de maiores transformações no campo, e as mulheres inseriram-se nessas mobilizações.

As reivindicações femininas encontraram eco no campo rio-grandense por causa das forças modernizadoras nas décadas de 60 e 70, que expulsaram grande contingente de pequenos agricultores do campo e deram lugar aos empresários rurais. Como o papel do governo e a exclusão dos pequenos produtores eram tão evidentes, acredito que podem ter funcionado como "mechas" na ação social dos agricultores.

3 A linha da Igreja Católica no Brasil que adotou a Teologia de Libertação, considerando o combate à pobreza como uma responsabilidade da Igreja, estando preocupada com a pobreza que atingia grandes setores da população. 
A modernização também alterou a organização interna dos pequenos estabelecimentos, onde, diretamente relacionada à posição social da mulher, ocorreu a perda da autoridade masculina, o que teve uma enorme influência no espaço da mulher. O espaço da mulher também mudou com a redução do índice de fertilidade. Essa nova situação foi uma pré-condição essencial para o surgimento e a expansão do movimento. A forma rígida como as mulheres tinham desempenhado suas funções se flexibilizou, e a idéia de que os padrões tradicionais de gênero talvez fossem mutáveis e variáveis germinou.

Os diversos "intermediários" no movimento forneceram diferentes elementos para a emancipação das agricultoras rio-grandenses. Um grupo de intermediários, as religiosas, estacava o respeito, a valorização e o trabalho das mulheres, dava consolo e esperança àquelas que, na vida cotidiana, enfrentavam grande desigualdade e fornecia-Ihes argumentos da Bíblia para que se levantassem contra a opressão e alcançassem a "libertação". Foi através das religiosas que as agricultoras começaram a participar ativamente na renovação sindical que formou o gérmen da mobilização social no campo rio-grandense, na abertura política. A ligação com o sindicato permitiu "traduzir" a valorização do trabalho em reconhecimento profissional e entrar na demanda por benefícios sociais. Quando, entre 1984 e 1987, o sindicato trocou o discurso religioso por um discurso socialista, desapareceu a base ideológica da organização em torno de assuntos femininos. Nessa época, foi fundada a Central Única de Trabalhadores no Estado - CUT-RS, e se procurou uma base de apoio no campo. As lideranças do sindicato identificavam-se com o Partido dos Trabalhadores (PT), e o espaço sindical formava parte da campanha em vários municípios. A ligação do sindicato de cunho combativo ao PT levou a um distanciamento com a Igreja e foi recebida pelos colonos com certa suspeita. 
Sociologias, Porto Alegre, ano 5, no 10, jul/dez 2003, p. 412-442

A secularização da identidade representou uma mudança de uma identidade que era ampla e inclusiva - inspiração religiosa- a uma que era exclusiva em base de fundamentos ideológicos - isto é, somente aquelas completamente engajadas na transformação socialista pertenciam. As aspirações transformadoras ou revolucionárias da identidade católica pertenceram (...). Elas substituíram a idéia da Teologia da Libertação da luta por liberação entre 'os pequenos e os grandes' pela luta de classe mais convencional entres os 'projetos econômicos, políticos e ideológicos da classe trabalhadora' e a 'burguesia'. O projeto do trabalhador, era, naturalmente, socialismo, não o Reino de Deus (Houtzager, 1997, p. 137-140, tradução própria).

Segundo a ideologia socialista, a sociedade socialista traria igualdade para todos, e a idéia de classe abrangeria todas as desigualdades, idéia que representava um grande contraste com as perspectivas das mulheres, que eram "alimentadas" tanto com o discurso de igualdade religiosa como com o exemplo das mulheres do sindicalismo "pelego". Com a Comissão Pastoral de Terra (CPT), as agricultoras formaram o movimento estadual em 1989, para, somente depois, abraçar a proposta do feminismo, explorando os direitos individuais e as relações de gênero existentes, com um tipo de feminismo popular adaptado às circunstâncias no campo e, ao mesmo tempo, elas conseguiram a garantia dos direitos sociais na Constituição de 1988. Mesclando elementos de diferentes fontes, as agricultoras marcaram presença política, baseadas em seu "próprio jeito de ser mulher". 


\section{Deus amava a todos igualmente}

No entendimento das religiosas envolvidas no movimento e responsáveis pela produção de grande parte do material do movimento, as muIheres eram supostamente complementares aos homens e, portanto, sua participação era imprescindível na "luta" da organização e na vida diária.

A farinha, o sal, o fermento, a água, os ovos, separados não formam o pão. Unidos pelo trabalho da mulher e do homem formam o pão. Cada ingrediente tem algo de específico para o pão ficar saboroso. Assim a muIher e o homem têm algo muito próprio para a felicidade de família, a união da comunidade e a organização justa, fraterna e igualitária da sociedade.

Então, cada um tinha sua própria tarefa para concretizar o projeto coletivo da "nova sociedade". Nessa complementaridade, "Deus amava a todos igualmente" e "Jesus consagrava a dignidade da mulher". Da mesma forma que os pobres eram representados como mais "puros" que os ricos, as mulheres eram representadas como mais "puras" que os homens, estando mais perto da "fonte da vida" pela sua função na reprodução. A mulher era representada como mensageira "da vida nova", de forma paralela à proclamação feminina da ressurreição de Jesus na Bíblia.

Essa fonte de vida era onipresente e referia-se tanto ao papel biológico como ao papel social e espiritual da mulher. Gerar vida também era indicado como o seu papel espiritual, visto que as mulheres, no sistema ideológico do machismo/marianismo, são consideradas superiores aos homens espiritualmente. Foi isso que legitimou a presença das mulheres na esfera pública da comunidade, fora de seu âmbito por excelência, a casa. Porém a Igreja Popular não somente legitimava a presença da mulher na comunidade como a destacava como necessidade para "fermentar a luta" dos pobres, com o seu valor espiritual e servil. "A quem tu serves" foi ampliado para o nível da comunidade carregada de sabedoria espiritual. 
A participação possibilitava às mulheres aderirem ao espaço público, tradicionalmente masculino e, assim, colocarem interrogativas à estrita divisão entre esfera pública e privada. Além disso, as mulheres aprenderam a enxergar a política de outra forma. Além de destituir a política de sua carga negativa, as mulheres familiarizavam-se com a política como assunto de todos e, assim, também seu. A religião, âmbito de atuação feminina tradicional, "abençoou" e legitimou a área política para as mulheres, promovendo, por conseqüência, a sua entrada na esfera pública.

\section{As "parteiras religiosas"}

As religiosas mostraram uma grande versatilidade e motivação para organizar as pequenas agricultoras, equipadas que estavam com o capital simbólico da tradição eclesiástica. A identificação das religiosas com as Mulheres da Roça tinha um caráter muito subjetivo, uma vez que a emancipação feminina era parte de sua própria vida pessoal e profissional. Sendo Maria no âmbito público, as religiosas podiam dar forma a seu próprio descontentamento e desvalorização, tendo em vista as dificuldades que enfrentavam para alcançar igualdade com os homens dentro da Igreja. Além do fato de que várias das religiosas conheciam bem a realidade do campo rio-grandense, a posição secundária na Igreja pode explicar a forte motivação de muitas religiosas para trabalhar com as pequenas agricultoras. As religiosas, inspiradas na Teologia de Libertação, desenvolveram junto às agricultoras a vivência da religião igualitária como alternativa à vivência religiosa hierárquica liderada pelos homens.

Contudo, apesar de sua grande influência sobre as agricultoras, as religiosas não tinham toda a liberdade para trabalhar com elas. A posição secundária na Igreja também significava que, se as religiosas constituíam o "elo" com a população local nas comunidades, era preciso o aval do bispo para facilitar a organização formalmente, no que dizia respeito não só à 
logística, mas também à legitimação das mensagens das religiosas. É evidente que a intervenção das religiosas na organização das agricultoras foi fundamental, mas não sem o apoio formal da Igreja por parte dos bispos e dos padres. A oposição eclesiástica foi um real e sério empecilho para o movimento, e, nos municípios onde houve uma maior liberdade de atuação ou até apoio da Igreja, o movimento teve maior possibilidade de desenvolvimento.

\section{Direitos sociais}

A intervenção das religiosas não somente provia as agricultoras de uma base ideológica para interpretar a nova realidade, mas também para aprender a linguagem de direitos sociais.

Como os homens, as mulheres na roça também tinham o direito de ser reconhecidas como trabalhadoras rurais. Destacava-se a abrangência da função feminina com os cuidados no lar e o trabalho na lavoura, possibilitando, assim, a manutenção da propriedade. Dessa forma, a defesa da emancipação social das agricultoras acontece por ser notório que as atividades das mulheres possuem valor (econômico), conseqüentemente, deveriam ter direito à cidadania por seu papel econômico e social como produtoras rurais. Para garantir essa inserção social das agricultoras de forma adequada, era necessária sua participação política, uma vez que o governo somente cederia, com pressão, defendendo sempre os interesses dos ricos. Como o governo tem poder, suas estratégias são obscuras, e as mulheres são individualmente invisíveis, é preciso, pois, uma organização coletiva. A organização, então, é pré-condição para se superar a situação e fazer justiça. E, também, uma expressão do desejo da igualdade com o homem, que tem o direito de se organizar. As agricultoras, então, são atores políticos com um papel importante na transformação da sociedade civil e política. 
As mulheres tiveram, nos municípios, um papel principal na instalação dos sindicatos de cunho combativo. Como a legislação existente tinha proibido o sindicalismo livre e somente permitia a criação de um sindicato de uma mesma categoria profissional por município, a forma de implantar o novo sindicalismo teria de acontecer através das votações. Dessa forma, "tomar" ou "ganhar" os sindicatos da Fetag era a primeira preocupação do novo sindicalismo, o que se fez através de discursos para convencer a população a votar em seus representantes. Várias mulheres inseriram-se na luta pela conscientização da população sobre a necessidade de mudança no campo, pois, nas reuniões dos grupos femininos, decidiu-se que todas iriam voltar para suas casas e tentar convencer seus maridos a votar na "chapa dois", que representava o sindicalismo de cunho combativo. Assim, dentro de casa, as mulheres, tentavam influenciar os maridos nas suas decisões políticas, o que se mostrou uma eficaz estratégia: gradualmente, os sindicatos da Fetag iam "caindo", dando lugar ao sindicalismo combativo em vários lugares.

No entanto, com a instalação dos novos sindicatos nos municípios, as agricultoras enfrentavam forte oposição para sua participação formal no sindicato, tanto na condição de membros da direção como na condição de sócias. O reconhecimento foi alcançado na maioria dos municípios, mas a inclusão dos assuntos femininos na agenda dos sindicatos mostrou-se difícil ou impossível de conseguir. Foi o contraste entre a intensidade do envolvimento feminino e a resistência masculina que levou as agricultoras a reivindicarem uma organização autônoma, independente e não subordinada a outras entidades rurais, nem à Igreja. As agricultoras "sentiram na pele" a desigualdade de gênero, que viam refletida na sociedade e nos movimentos e sindicatos. O reconhecimento profissional e a concessão dos direitos sociais das agricultoras na Constituição de 1988, finalmente, ofereceu-lhes o estímulo para, de fato, reivindicar esse espaço independente. 
A formação de um caráter próprio do movimento e o distanciamento da Igreja foram reforçados com uma assessoria feminista nos primeiros anos, que trouxe preocupação com os direitos individuais da mulher como pessoa, além de seu valor como produtora. Naquela época, as mulheres da classe média no Brasil estavam descobrindo as idéias feministas como uma alternativa para sua própria vida. Entre outras atividades, as mulheres formavam grupos de discussão, nos quais a própria experiência com temas como sexualidade, identidade feminina e masculina, o rejeito dos papéis tradicionais e a necessidade da criação de novas identidades eram centrais. Como tal, o feminismo foi levado às mulheres agricultoras, como uma experiência pessoal das assessoras. Em conjunto com as agricultoras, aquelas construíram um tipo de "feminismo popular", foi um processo contraditório e difícil, pois as idéias feministas eram dificilmente aplicáveis às mulheres do interior.

Essa mulherada vem muito na Igreja, então questionar a Virgem Maria era uma coisa difícil. Depois levava esse trabalho de um jeito diferente. Sem puxar o tapete deles. Eu não podia chegar com a minha realidade. Quando fiz isso, dei com os burros na água, me equivoquei. A minha necessidade de discutir aborto e brigar por aborto na sociedade, tive que colocar em outro espaço. O meu trabalho é aqui e vamos ver o que cabe para discutir. Para que vamos brigar? Em vez de brigar por aborto, vamos discutir para a mulherada sair sábado de tarde para o lazer delas, o que não era fácil. Aprender a dizer para o marido, para a vizinha, hoje não vou limpar tão bem a casa porque estou indo jogar vôlei. Eu revolucionei a vida delas nessa coisa do cotidiano, e a minha também junto, oportunizando para elas uma discussão que não estava feita ainda. E para 
Sociologias, Porto Alegre, ano 5, no 10, jul/dez 2003, p. 412-442

mim foi obscuro por causa disso. Se fosse militar num movimento urbano de classe média, sem problemas, agora, lá foi de certa forma experimentar mesmo, ver até onde dava para ir (assessora do MMTR-RS entre 1989-1992).

Nos debates e cursos com a assessoria feminista, a ênfase estava na valorização. Contudo, à diferença do discurso das religiosas, era uma autovalorização das mulheres como seres humanos individuais, com o direito de serem felizes, de saírem de casa quando quisessem e de mais capacidades do que "fazer um bolo". As feministas trouxeram a discussão sobre direitos individuais.

\section{Direitos e democracia}

A mudança de maior impacto e mais concreta ocorrida para as agricultoras, a partir da fundação do movimento, foi a garantia dos direitos sociais na Constituição de 1988, que atingiu a toda a categoria das trabaIhadoras rurais e mudou radicalmente a posição da mulher rural. Pela primeira vez, foi concedido o direito à previdência às mulheres rurais, consistindo na aposentadoria, no salário-maternidade e no auxílio-doença, que entraram em vigor no início da década de 90. Os homens beneficiaram-se com a redução do limite de idade, que passou de 65 para 60 anos, e o aumento do benefício, de meio salário para um salário mínimo.

Para o MMTR, a concessão dos direitos previdenciários representou a confirmação da capacidade política do movimento e, assim, das mulheres agricultoras. Essa capacidade refletiu-se também no maior prestígio do movimento entre o conjunto de movimentos rurais depois da concessão dos direitos. A concessão, ainda, foi importantíssima na identidade do movimento atual, pois as trabalhadoras rurais, pela primeira vez na história 
brasileira, tinham reivindicado "o direito a ter direitos" e exigiam voz, vez e voto na arena política. Sua inclusão na Constituição foi, portanto, considerada pelo próprio movimento MMTR-RS como uma "recompensa" por seu esforço, como também a concessão concreta dos direitos, que representou um processo árduo e difícil de vários anos e que ainda continua.

Observando a concessão dos direitos previdenciários de um ponto de vista político, fica evidente que a concessão dos direitos para as agricultoras fez parte da estratégia de "tranqüilizar" o meio rural e não representou, na verdade, uma expansão da cidadania. Além disso, a garantia desses direitos, na prática, tem sido obtida apenas parcialmente e, ainda assim, eles cumprem a função de uma renda fixa. Com "duas vacas e uma aposentadoria" as agricultoras indicaram poder sobreviver.

O início da ampliação dos direitos previdenciários para a população rural acontecera durante a ditadura militar (1964-1984), através da criação do Funrural. No início da década de 70, fora concedido o direito de aposentadoria aos homens trabalhadores rurais, na forma de meio salário mínimo. Em comparação com os trabalhadores urbanos, a concessão dos direitos previdenciários aos trabalhadores rurais foi muito mais tardia.

A expansão da cobertura previdenciária no campo aconteceu pelo valor estratégico do setor rural no modelo desenvolvimentista e pelo temor do governo de que o sacrifício do setor dos pequenos produtores iria resultar em importantes mobilizações rurais. Enquanto o governo apoiava o empresário rural com grandes subsídios, os pequenos agricultores ficavam abandonados à sua sorte, com poucas perspectivas. Foi este forte contraste no próprio meio rural que mobilizou os colonos no Rio Grande do Sul, tradicionalmente um grupo conservador e com pouca consciência política. A concessão e a ampliação de serviços médicos e benefícios monetários também constituíam uma estratégia para reduzir a imigração dos agricultores para os centros urbanos, visto que a urbanização acontecia em um ritmo muito elevado e acima das possibilidades de expansão de mora- 
dia e emprego. A base ideológica da integração rural no desenvolvimento nacional, segundo Schwarzer (2000, p. 75), era formada pela doutrina de segurança nacional, que considerava a criação de "justiça social" necessária para a manutenção da "paz social". Além disso, a tecnocracia previdenciária identificava-se com o mainstream da época, orientado por princípios da OIT, que propunha a universalização da cobertura.

Portanto, o exemplo da concessão dos direitos sociais ao setor rural mostra a ligação da extensão da cobertura previdenciária com as práticas populistas no Brasil. Como foi através de financiamento que o governo excluiu a maior parte da população rural, esta começou a reivindicar a cidadania com esta perspectiva, ou seja, enfocando os direitos sociais, na forma de retribuições econômicas. Uma das conseqüências dessas práticas é uma consciência fraca das pessoas sobre os seus direitos, como se pode observar em toda América Latina (Jelin, 1997, p. 66). Significa isso que os direitos não são considerados como parte comum da cidadania e sim como direitos de todos, senão como "privilégios" para alguns.

A situação no Brasil parece indicar que a consolidação da democracia não necessariamente significou a ampliação e a aplicação concreta do conjunto dos direitos que compõem a cidadania, como é o caso no modelo de Marshall (1950). Caldeira (1998, p. 85) considera o Brasil um exemplo de um país com uma democracia "partida" (disjunctive), no qual somente parte dos direitos é garantida, enquanto a outra parte não é respeitada. Amplos setores da população têm agora acesso aos direitos sociais, o que ajuda as pessoas na sua sobrevivência; contudo, esses direitos não têm sido considerados como parte comum da cidadania. Além disso, os direitos sociais eram ligados ao trabalho, como que excluindo muitas muIheres, ora por trabalharem como donas de casa ou como agricultoras, ora por trabalharem na esfera informal como domésticas.

Um outro ponto relevante na área dos direitos faz referência à ordem cronológica da concessão dos direitos. A situação no Brasil revela outras 
circunstâncias que supõem o processo cumulativo de Marshall (1950), pois, de acordo com Caldeira (1998, p. 85), a violência estatal e civil tem aumentado no país após a instalação da democracia em 1985. Grandes setores da população vivem na pobreza e carecem das mínimas condições de acesso a informações sobre o funcionamento da sociedade, não podendo, por isso, interpretá-las. Ao mesmo tempo, a cultura política brasileira parte do conceito do cidadão "livre", que tem livre acesso aos meios e, por conseqüência, a uma boa posição num mundo competitivo. A ausência do governo como protetor dos mais vulneráveis justifica-se pela posição de competição que o Brasil precisa manter na sociedade mundial.

O problema mais grave do Brasil, segundo Caldeira (1998, p. 86-87), está na esfera dos direitos individuais e civis e do sistema judiciário, responsável pela garantia desses direitos. Enquanto os direitos sociais formam a parte mais legitimada, os direitos individuais e civis formam um elo que falta na democracia brasileira. Freqüentemente, esses direitos não são respeitados, e o sistema judiciário, adequado ao funcionamento nas ditaduras, é fraco como instituição de garantia. A falha do sistema judicial faz parte da vida cotidiana no Brasil e acarreta que as pessoas sejam e se sintam muito vulneráveis, especialmente aquelas sem nenhum meio para se proteger. O corpo e a pessoa geralmente não são protegidos por direitos, o que significa que não são estabelecidas barreiras e limites à intromissão, intervenção, ou ao abuso dos outros. As mulheres são mais vulneráveis nesse sentido.

A relação das mulheres com o Estado não se dá somente como uma busca de proteção, mas como uma oposição à violência estatal. A ação social em massa das mulheres nos países em desenvolvimento mostra, além do seu poder como uma força mobilizadora, as dificuldades profundas que as sociedades enfrentam para organizar as atividades reprodutivas, domésticas, produtivas, comunais e políticas de forma igualitária para homens e mulheres, sendo que o Estado falha em garantir a sobrevivência da 
família (Chowdhury et al.,1994, p. 5-6). As reivindicações das mulheres tocam no bojo dessa questão.

No que diz respeito aos direitos políticos, esses são formal e amplamente reconhecidos pela população brasileira. Contudo, além de uma grande desconfiança no sistema jurídico, a população não confia na vida política, nem nos políticos. Para grandes setores da população, os partidos políticos não formam canais legitimados para traduzir suas aspirações e perspectivas, mas, sim, servem aos interesses próprios dos políticos. Portanto, a vida política é vista como uma troca de interesses em que o pobre sempre perde, mas pode tentar conseguir alguma coisa. Isso ocorre em épocas de eleições, quando as pessoas pobres nos bairros da cidade e no campo recebem visitas dos políticos, os quais thes prometem tijolos, cirurgias, sapatos, ruas asfaltadas; são essas atitudes clientelistas, cooptativas, populistas e corruptoras, comuns na vida cotidiana e confirmadas pela mídia. A falta de transparência nas atividades do governo, a grande quantidade de partidos políticos, a tradicional valorização das características pessoais acima da mensagem do partido e a pobreza mantêm essa situação. Obviamente, isso tem conseqüências para os direitos políticos da população e dá uma outra conotação ao voto "livre" e ao direito de votar.

Em todo esse contexto de caráter ambivalente da democracia brasileira, devem, no meu entender, ser situados os movimentos de mulheres atuais. Seguindo o desenvolvimento dos movimentos sociais no Brasil, talvez ampliados para toda a América Latina, parece evidente que os movimentos sociais não levam a transformações políticas radicais, pelo menos a curto prazo. No entanto, acredito que os podem levar a transformações menores nas relações de poder e valores culturais na vida diária e na prática de política institucional. A dimensão cultural dos movimentos é significativa para entender o seu surgimento e dinâmica, já que os movimentos são respostas baseadas em significados culturais, formadas no contexto da vida diária, com seus limites e necessidades sentidos. 


\section{Prazer e conhecimento}

Teresa (39 anos) já não pode imaginar a sua vida sem o movimento. Para ela, o movimento de mulheres foi uma Faculdade, que lhe ofereceu muita informação relacionada à mulher que ela não sabia: "Do corpo, do valor [da mulher], nós temos que nos valorizar e não esperar que os outros nos valorizem. Se gostar da gente mesmo. Isso foi tudo dentro do movimento. Cursos, o que tinha, eu participei em tudo".

Como Teresa, muitas mulheres formaram parte do MMTR-RS, a maioria na mesma faixa etária. Elas destacaram o sofrimento provocado pela desinformação, que marcava a sua vida anterior ao movimento. Tradicionalmente, a sexualidade feminina servia à função de manutenção da coletividade da família e da propriedade agrícola, de acordo com o sistema ideológico vigente. Na roça, isso era fundamental uma vez que garantia a continuidade da força de trabalho e, assim, do estabelecimento.

As agricultoras contaram que as poucas informações recebidas eram passadas nas "entrelinhas", de mãe para filha, dentro de um imaginário em que o corpo e o sexo eram relacionados com o pecado. Assim, desenvolveram-se o medo e a vergonha em relação ao sexo e aos homens, que, nesta visão, roubavam a "pureza" das mulheres, o que resultava numa grande falta de conhecimento. "Até o dia de meu casamento, eu não sabia de onde vinham as crianças. Diziam que vinham do banhado. Depois pensava que cada vez que se fazia sexo crescia o nenê. Comecei a entender depois". ${ }^{4}$

Tratar dos assuntos relacionados ao corpo, como o MMTR-RS fazia, constituía uma verdadeira provocação à tradição dominante no campo rio-grandense.

Colocar aquilo para as mulheres da comunidade era um absurdo! Isso não poderia existir. Imagina, era uma coisa! De se falar, por exemplo, para a mulher 'quantas vezes você foi para a frente do espelho, te tira a roupa

4 Liderança MMTR-RS, 55 anos. 
e te olha lá, Deus me livre! Isso era para botar a mão na frente do coração. Que você se dá conta que é uma mulher. $^{5}$

Embora a informação sobre o corpo e a sexualidade que o movimento lhes tem oportunizado seja revolucionária, foi apenas gradualmente que as mulheres entraram nesse outro mundo de valores diferentes. A situação era diferente para muitas mulheres jovens, que tinham sido educadas com outros valores, entre outros, nos grupos pastorais. Como essas estavam mais convictas nos novos papéis de gênero, elas iam desempenhando um papel crucial no processo de formação do movimento.

Participar do movimento foi destacado por todas as participantes como um grande prazer, não somente pelo conhecimento obtido, mas também pelo carinho e amizade com as outras mulheres e pela valorização como pessoa, que contrastam com a carência sentida em casa.

A funcionalidade nos relacionamentos entre os casais italianos na roça se caracteriza, de forma geral, pela autoridade masculina e pela ausência de mostras de carinho e diálogo. Os homens geralmente não consultam as mulheres nas decisões de compra, não as informam sobre as suas andanças e planos e são rudes no contato com elas. As mulheres, por sua vez, indicaram sofrer muito por causa da desconsideração dos homens e por se sentirem depreciadas, excluídas, sozinhas e isoladas. Uma mulher revelou sua enorme tristeza pelo fato de o marido nunca a ter chamado por seu nome. No movimento, o uso do próprio nome tornou-se importante já que é uma expressão da valorização da mulher, contrariamente ao costume tradicional de referir-se à mulher como "esposa de".

No trabalho de campo, encontrei muitos casos de depressão feminina, ou, como as próprias agricultoras dizem, "que sofrem dos nervos". Solidão, falta de contatos sociais, trabalho rotineiro, dupla jornada de trabalho, doença, difícil relacionamento com o marido e pobreza constantes

5 Liderança MMTR-RS, 43 anos. 
são algumas das razões indicadas. Exemplos extremos são os maus-tratos e outras formas de violência, que, no campo, são mais difíceis de perceber pelo isolamento das casas e ficam, freqüentemente, sem punição. Não se trata somente de violência contra as mulheres, mas elas ficam mais frágeis num ambiente violento por sua falta de proteção e poder. Além disso, uma roça com uma mulher sozinha é considerada "incompleta", como o que ela sofre de maior insegurança.

Além disso, em comparação com outros Estados brasileiros, há uma incidência muito alta de casos de mortalidade por câncer de mama e de colo de útero no Rio Grande do Sul. Estudos mostraram que 42\% das mortes das mulheres no Estado (rural e urbano) se devem a essas doenças, que são a principal causa da morte daquelas entre 30 e 49 anos. Principalmente o câncer de mama é freqüente, cujo índice de mortalidade, de 1980 a 1998, no Estado, subiu de 10,5 para 17,4 em cada cem mil mulheres. ${ }^{6}$ O MMTR-RS informa que esse fato está ligado à dupla jornada de trabalho, ao uso de agrotóxicos, à alimentação muito gordurosa e ao uso de pílulas anticoncepcionais. Há indícios de que o uso indiscriminado de agrotóxicos tenha aumentado em 20\% nos últimos anos, como também tem crescido o número de crianças que nascem malformadas.

Através do movimento, as mulheres recebem consolo e amizade das companheiras e podem canalizar seus medos, angústias e frustrações. Portanto, embora de formas diferenciadas, a participação no movimento parece significar a criação de um lugar único de emancipação individual e coletiva. O movimento propicia-lhes a oportunidade de prestarem atenção a si mesmas como pessoas, de conhecerem melhor o seu corpo. No movimento, as mulheres aprendem que é bom tomar um banho diário, mas também que devem tomar a pílula anticoncepcional com controle médico; também aprendem a desenvolver certas habilidades, como, por exemplo, dialogar, discutir, organizar-se, ler a Bíblia, solicitar alguma coisa 
do vizinho, fazer os trâmites bancários e lidar com o dinheiro, com o sindicato. Elas disseram que sofriam com o isolamento em casa, que fazia os problemas parecerem ainda maiores; assim, gostaram de ter aprendido que "o mundo é maior do que as quatro paredes", "esquecer da vida e do serviço", "sentir que é bom dar risada" e divertir-se com outras mulheres agricultoras.

Nessa esfera de intimidade com mulheres fora de seu âmbito familiar, as agricultoras desenvolvem atitudes e formas de convivência alternativas às que estavam acostumadas em sua vida cotidiana. Ao invés das relações de autoridade, desenvolveram relações de carinho e colaboração, baseadas na igualdade e na valorização de cada pessoa. Através da convivência de confiança, num ambiente seguro, elas quebraram o isolamento em casa e começaram, como diziam freqüentemente, a "se sentir gente", a criar "mais autovalorização e respeito", conforme aumentava sua participação nas reuniões.

As mulheres inseridas na ação coletiva tentam reconciliar os seus desejos de auto-realização com o afeto e o cuidado para com a família. Um elemento crucial nesse desenvolvimento da auto-realização é o "cuidado para o outro", desta vez não dos familiares, mas das amigas, das companheiras do movimento. Em vez do sentido único no cuidado no âmbito privado, no âmbito público, a troca é essencial. É a troca da atenção e carinho que permite às mulheres o prazer de participação. É o carinho mútuo na forma de um ouvido, de um abraço de pessoas que se encontram em circunstâncias e necessidades parecidas. Isso significa que a cidadania não é o referencial para a participação política das mulheres nos movimentos populares. Segundo Alvarez (1990, p. 50), a maternidade é essa referência, o que pode ser confirmado na presente pesquisa. As agricultoras são 'tocadas' pelas políticas do Estado e o elemento do "cuidado para o outro" motiva-as para a participação. 


\section{Maternidade militante}

Conforme Schmuckler (1995, p. 142), na participação no movimento trata-se da entrega pessoal isolada no âmbito privado, versus a solidariedade ou a cooperação entre mulheres no âmbito público, ou seja, a "maternidade privada" contra a "maternidade militante", porque "incorpora los elementos de cuidado del otro que caracteriza a la maternidad tradicional pero con un sordo desprecio del aislamento y la devaluación de la mujer madre" (Schmuckler, 1995, p. 142). Mas isso não significa que o altruísmo leve as mulheres à participação política. A maternidade pública ou social (Schmuckler, 1995, p. 38) Ihes traz algo extra que a maternidade privada - "cúmplice central da subordinação feminina" (Schmuckler, 1995, p. 38) - não lhes dá: estimula um processo de auto-realização que se trata da satisfação das suas próprias necessidades de mulher e que a leva à participação da cidadania.

Na visão do custo/benefício, as relações de afeto e o novo saber representaram o grande benefício da participação, em contraposição às dificuldades encontradas para garantir sua presença nas reuniões, por causa das tarefas e expectativas do seu papel em casa. As agricultoras disseram ter maior auto-estima e coragem para se defender e opinar: "Eu fui pisada por todo o mundo, meu pai, meu esposo, os sogros, mas não sabia como me defender. Agora eu sei". ${ }^{7}$ Ou como conta outra liderança: "Mudou meu jeito de agir. Quando me pisoteiam, pisoteio também. Me defendo e brigo. É bom ser um pouco mais dona da vida da gente ${ }^{\prime \prime}{ }^{8}$ Ou seja, na convivência, elas vão desenvolvendo e adquirindo uma identidade feminina alternativa, em que experimentam a possibilidade de decidirem sobre suas próprias vidas e de terem o direito e a capacidade de fazer isso. No seu papel familiar, as mulheres vão descobrindo novas fronteiras, lugares, possibilidades e reconstruções. 
Esse processo não é linear, mas, sim, uma busca de soluções com legitimidade externa e inseguranças internas, com um antagonismo entre a rebeldia e a submissão (Paoli, 1995, p. 92), entre o desejo de responder a suas próprias necessidades pessoais e a identificação com o seu papel familiar, entre o altruísmo público e o privado (Schmuckler, 1995, p. 142). Os problemas pessoais tornam-se problemas de todas e, pela reflexão, as mulheres aprendem a ter uma nova leitura sobre suas vidas e existências. $\mathrm{Na}$ coletividade, elas começam a explorar sua cidadania como mulheres e como parte de uma categoria profissional; comparam-se com as mulheres urbanas e com os homens de sua mesma classe, que ocupam posições melhores que a sua. As agricultoras descobrem a desigualdade de gênero e começam a utilizar uma linguagem de direitos. Tal comparação alimenta sua convicção de que estão agindo certo, que estão pedindo coisas justas e que é esta uma alternativa necessária: "Se nós não [fôssemos] no movimento, não sei o que seria de nós". As mulheres formulam demandas efetivas aos governos local, estadual e federal e tentam influenciar na vida política; portanto, as agricultoras passam por um processo de emancipação individual e, ao mesmo tempo, coletiva, na busca de respostas locais às carências sentidas.

Observei como, em decorrência do crescimento pessoal das agricultoras na integração da dinâmica do movimento, as relações sociais e familiares tendem a mudar na direção de um maior espaço de atuação da mulher. Esse processo acontece gradualmente e, freqüentemente, sem prévia intenção. Uma mulher participa de uma manifestação do movimento na cidade próxima, aproveitando que o sindicato dos trabalhadores apóia a manifestação e que o marido também participa. Se ela julgou importante o evento e a cunhada convida-a para uma reunião na comunidade, tenta aproveitar um momento adequado para solicitar permissão ao marido para participar, assegurando-lhe que deixará tudo pronto e que a filha ou a irmã preparará o almoço em seu lugar. Assim, ela cumpre com o seu 
dever de cuidar da alimentação, que tanto ela mesma como os outros membros da família consideram como sua obrigação. Se gostou da reunião com as outras mulheres e pensa em participar de outras, certamente, ela agirá da mesma forma.

Quando a mulher quer fazer parte do movimento de forma estrutural, porque a participação nele está proporcionando-lhe satisfação, ela vai ampliando seu espaço de negociação, buscando a aprovação do marido e a superação de seu próprio sentimento de culpa. Assim, com o passar do tempo, o "pedir" permissão ao marido vai-se tornando negociação com o marido, ou seja, ela começa a perceber a participação como um direito. Este processo se tornará mais ou menos intensivo e comprometedor dependendo da situação particular da liderança. Poucas agricultoras da base conseguem uma divisão de tarefas domésticas igualitária, na qual os maridos se preocupem tanto como elas com o funcionamento da esfera doméstica.

Geralmente as agricultoras tendem a criar esses espaços "driblando" o tempo; assim, elas fazem muitas atividades ao mesmo tempo, ou em outros horários, para não "sacrificar" o tempo da família com as atividades do movimento. Aproveitam uma visita à vizinha para levar verduras e falar sobre a organização de uma manifestação em Porto Alegre ou sobre a próxima reunião do movimento; para repassar notícias a mulheres que moram longe, elas utilizam o leiteiro como intermediário. Para poderem participar dos encontros, antes de sair, elas se sobrecarregam de trabalho, deixando pronto o máximo que podem e, quando voltam, têm de fazer todo o trabalho que não executaram durante sua ausência, o que gera, muito provavelmente, tensões familiares. Tudo acontece dentro de um espaço legitimado do papel feminino, que pouco a pouco vai-se ampliando.

Busca-se a criação de um espaço feminino, por um lado, com idéias que confirmam a natureza feminina rural e, por outro, com idéias inovadoras que contrastam fortemente com a cultura existente. Em comparação 
com as mulheres urbanas, por exemplo, as mulheres da roça estão mais próximas da natureza, o que lhes atribui tanto o conhecimento de plantas e da alimentação como de poderes curativos. Em alguns lugares do interior, as mulheres fazem pequenas farmácias ecológicas, atuando como bruxas, num sentido positivo, como mulheres guardiãs da saúde da família e mulheres sábias, poderosas, curandeiras, mágicas e respeitadas na sua comunidade. A "mística" ${ }^{9}$ que as religiosas desenvolveram junto com as agricultoras é baseada nessa idéia da natureza feminina rural. Além do companheirismo, as mulheres sentem a presença de Deus através da mística, que consideram imprescindível para o bom funcionamento do movimento.

Os significados culturais desenvolvidos na criação de uma identidade coletiva são representações alternativas para redefinir as relações de poder na sociedade e na vida cotidiana. As palavras são cruciais nesse processo, especialmente num movimento como o MMTR, onde a fala e a leitura são essenciais.

\section{Vida diária}

A vida diária torna-se a esfera principal e referência nos movimentos sociais, a partir da qual as mulheres vão criando suas representações de resistência na sociedade civil. Os movimentos sociais não podem ser entendidos, sem conhecer a vida diária do grupo social em questão porque é o âmbito em que se produzem os significados culturais (Alvarez, Dagnino \& Escobar, 1998).

Criatividade simbólica na vida cotidiana é vibrante, bem como algo invisível; envolve linguagem, o corpo, ritu-

9 Atividades e rituais espirituais ou (semi) religiosos que visam reforçar a identidade coletiva através dos símbolos, cantos, poemas e histórias. 
ais de execução, trabalho e identidades tanto individuais quanto coletivas. É essencial para a pesquisa de movimentos sociais explorar esse nível de práticas populares. A vida cotidiana envolve um ato coletivo de criação, um significado coletivo, uma cultura. É desse depósito de significados (isso é, uma 'tradição') que pessoas realmente dão forma à sua luta. Colocado numa forma mais abstrata e geral, a vida diária é localizada na intersecção de processos de articulação de significado através de práticas, por um lado, e macroprocessos de dominação, por outro (Escobar, 1992, p. 71, tradução própria).

Os movimentos formam espaços de representação na conflitante vida cotidiana, nos quais as tensões são evidentes, e as mulheres se tornam atores públicos, capazes de interpretar as desigualdades sociais, de reclamar pelas injustiças feitas e de entrar em um diálogo público. Fazendo isso, as mulheres vão reelaborando as condições de sua existência, em termos de tradição e necessidades; vão rompendo hierarquias simbólicas que as mantiveram numa posição subordinada de exclusão e discriminação. Como Dagnino (1998) afirma:

Como parte do ordenamento social autoritário e hierárquico da sociedade brasileira, ser pobre não somente significa sofrer privação econômica e material, mas também ser submetido a regras culturais que expressam uma falta completa de reconhecimento de pessoas pobres como sujeitos, como portadores de direitos. No que Telles (1993) chamou de incivilidade embutida nesta tradição, pobreza é um sinal de inferioridade, uma forma de ser na qual os indivíduos perdem a sua habilidade de exercer seus direitos. Essa privação cul- 
Sociologias, Porto Alegre, ano 5, no 10, jul/dez 2003, p. 412-442

tural imposta pela absoluta ausência de direitos, que ultimamente se expressa como uma supressão da dignidade humana, torna-se então constitutiva de privação material e exclusão política (Dagnino, 1998, p. 48, tradução própria).

Acontece na organização feminina uma extensão da esfera democrática, pela qual as mulheres fazem experimentos como cidadãs em um laboratório, o que pode servir para convertê-las em pessoas conscientes de seus direitos e capazes de reivindicá-los. Assim, os direitos se estendem à esfera da autonomia pessoal, e a mulher se insurge contra condições que são opressivas e restritivas.

A partir desses laboratórios, acontece um processo que Schmuckler (1995) chama de "microdemocratização", ou seja, supõe-se que as muIheres que assumem posições de liderança incentivem mudanças emancipatórias, as quais se dão, primeiro, dentro da família e, depois, estendem-se a outras esferas diretamente ligadas à esfera familiar, como, por exemplo, a escola. Um processo parecido acontece, segundo Paoli e Telles (1998), quando a forma de fazer política é estendida às práticas políticas dos partidos, como ocorre nos orçamentos participativos, organizados pelos governos municipais petistas de várias cidades, como na capital do Estado do Rio Grande do Sul, Porto Alegre. Dessa forma, demandas populares podem ser introduzidas na administração pública, sem que, com isso, se entenda que todos os setores têm as mesmas necessidades. Aparecem, então, a possibilidade e a liberdade de participar no âmbito público como pré-condições para uma cidadania plena.

Um cidadão pleno no sentido mais completo é alguém que participa na legislação ou tomada de decisões em assuntos públicos. Concerne participação através da 
qual uma pessoa reflete sobre o caráter novo e desejável da sociedade e através da qual alguém renove a sociedade, cooperando com outras pessoas. É a participação em que alguém discute assuntos comuns com outros, reflete sobre bens comuns, aprende a tomar responsabilidade, a julgar e a decidir (Voet, 1998, p. 137, tradução própria).

A autora considera importante que as mulheres se formem como sujeitos políticos para que possam conhecer os seus direitos, mas também suas responsabilidades, desfrutando de seu status como cidadãs. Segundo Voet, a liberdade do cidadão é vazia se não está ativa; nas palavras de Craske (1999, p. 23), "it also requires change in the personal perception of the empowered subject". Empowerment, então, é um elemento crucial na cidadania para ter controle sobre a própria vida, ou seja, trata-se de poder para capacitação, e não de poder sobre outras pessoas.

A participação no movimento permitiu uma redefinição do papel das agricultoras, contrastando com seu papel tradicional na esfera doméstica e no interior das entidades rurais, com conseqüências importantes para seu bem-estar (em vários sentidos) e de sua família. Com a aposentadoria, a mulher ganhou uma certa independência econômica: além da compra da maior parte da alimentação para a família, permite-lhe também comprar alguns remédios e, o que é importante, administrar o seu dinheiro. Além do mais, com a crise atual na agricultura, esses direitos sociais tornaram-se cruciais para a sobrevivência dos agricultores. Não foi o movimento que ganhou esses direitos, mas esse contribuiu substancialmente para a formulação dos pedidos, sendo a única organização independente com uma agenda para as mulheres rurais num quadro de agricultura muito complexo.

Através do movimento, as mulheres rurais e sua problemática se tornaram visíveis e representadas no âmbito público; passam fazer parte do âmbito público em muitos lugares no interior e se formam politicamente. 
Isso é especialmente importante, tratando-se de uma categoria que nunca antes se tinha organizado. Elas tentam reverter a sua situação numa democracia partida (disjunctive), na qual os direitos parecem ser privilégios e compráveis. E, como Voet (1998, p. 45) afirma, "depois de tudo, pessoas com baixa auto-estima não podem ser atores políticos confidenciais".

Na minha opinião, o uso de gênero, no movimento, deve ser entendido como o potencial de mudança das normas antigas, que atribui às mulheres um papel silenciado, de conformidade, ignorância e sacrifício a serviço dos outros. Gênero significa que as agricultoras se levantaram contra o poder de decisão que os homens têm sobre elas, para poderem decidir sobre as suas próprias vidas. A maternidade e o cuidado do outro são centrais na inserção política das pequenas agricultoras, e, reivindicando a mudança nas relações de gênero, elas pedem um co-partnership no estabelecimento agrícola; querem preencher seu papel de mães e esposas de outra forma. Importante, para elas, é o envolvimento dos homens na mudança, já que a vida num estabelecimento agrícola é mais do que somente uma opção profissional. O trabalho da mulher está interligado com a sua vida afetiva e faz parte do contrato matrimonial (Carneiro, 1995, p. 352353). Essa realidade vivida dá uma conotação específica às formas nas quais as mulheres podem sentir-se oprimidas, diferentemente do que, por exemplo, pode ocorrer com as mulheres urbanas. Essas circunstâncias especiais fazem com que os interesses e demandas das mulheres rurais se diferenciem dos interesses das mulheres urbanas e, essencialmente, daqueles das feministas. A colaboração com o marido é a única forma por meio da qual a mulher pode fazer o seu trabalho diário e se organizar. Ela não chega a ter uma independência, pois o trabalho na roça limita a sua mobilidade de forma geral.

Antagonismos podem ser observados, por exemplo, no que diz respeito à influência da Igreja Popular na construção do movimento. O âmbito religioso potencializa as pequenas agricultoras para a ação social, sendo o lugar feminino por excelência. Contudo a Igreja destacou a importância da "maternidade pública", sem resolver o antagonismo desta com a "ma- 
ternidade privada". A Virgem Maria é uma importante referência de identidade para as agricultoras, tanto para sua atuação no âmbito privado como no público, mas certamente apresenta contradições para elas. Como De Theije (1999, p. 114) afirma, tratando das CEBs: "Os modelos diferentes e incongruentes de gênero são repassadas às mulheres e é a elas que cabe encontrar uma solução" (tradução própria) Além disso, a ênfase nos aspectos econômicos e nos valores femininos tradicionais negligenciou as dificuldades individuais das mulheres no árduo processo de alcançarem maior igualdade nas relações de gênero em suas vidas cotidianas.

No entanto, foi de mãos dadas com as religiosas que as agricultoras no Rio Grande do Sul desafiaram as relações autoritárias em diferentes âmbitos da vida cotidiana e construíram a sua cidadania no novo contexto. Sem o envolvimento das religiosas, as agricultoras, provavelmente, nunca teriam chegado à mobilização social. A forte identificação das religiosas e seu envolvimento especial com a problemática das agricultoras constituíram a base para uma organização de grande impacto na realidade existente e na formação de interesses. Posteriormente, os interesses formulados em conjunto com a Igreja mostraram-se insuficientes, com o que, foram formulados interesses na direção da mudança das relações de gênero, mas não tendo o homem como maior "inimigo", senão o governo.

Não se trata, portanto, da questão de se o movimento é estratégico ou não, mas como a organização e as demandas das mulheres são determinados pelos contextos históricos, econômicos, religiosos e políticos específicos. A ação social acontece num processo complexo em que vários âmbitos interagem de forma contínua.

\section{Conclusões}

O enfoque na ação social das mulheres trabalhadoras rurais revela como a política está entrelaçada com a vida diária. A análise da dimensão cultural e histórica do movimento confirma que os movimentos são espaços importantes para a reflexão e o debate, formados por relações 
interpessoais, em que são desenhados significados alternativos de "cidadania", "democracia", "igualdade", "direitos" e do que é "justo", desafiando definições do que se conhece como estritamente "político". Os movimentos tratam de "lutas" sobre direitos e significados e politizam o que não é político, desafiando a arena política para estender os seus próprios limites e ampliar a sua agenda. Os participantes desenvolvem-se como sujeitos políticos na conflitante e ambígua vida diária, problematizando demandas coletivas como representantes políticos legítimos. Essa representação tem um valor crucial, estando no eixo da democracia. Como tal, na realidade brasileira, com a democracia "partida", os movimentos podem dar uma contribuição essencial no processo de democratização e na direção da cidadania plena.

\section{Referências}

ALVAREZ, S.E.; Dagnino, E.; Escobar, A. Introduction: The Cultural and the Political in Latin American Social Movements. In: Alvarez, S.A.; Dagnino, E.; Escobar, A. (Ed.). Culture of politics: politics of culture. Boulder: Westview Press, 1998, p.1-29.

CALDEIRA, T. P. R. Justice and Individual rights: challenges for women's movements and democratization in Brazil. In: Jaquette J. S.; Wolchik S. L. (Ed.). Women and democracy: Latin America and Central and Eastern Europe. Baltimore: The John Hopkins University Press, 1998, p. 75-103.

CARNEIRO, M. J. Esposa de agricultor na França. In: Estudos Feministas, v. 4, n. 2, 1996, p. 338-354.

CHOWDHURY, N.; Nelson, B.; Carver, K. Redefining politics: patterns of women's political engagement from a global perspective. In: Nelson, B.; Chowdhury, N. (Ed.). Women and politics worldwide. New Haven: Yale University Press, 1994, p. 3-24.

CRASKE, N. Women and politics in Latin America. New Brunswick: Rutgers University Press, 1999. 
DAGNINO, E. The cultural politics of citizenship, democracy, and the state. In: Alvarez, S.A.; Dagnino, E.; Escobar, A. (Ed.). Culture of politics: politics of culture. Boulder: Westview Press, 1998, p.33-63.

ESCOBAR, A. Culture, economics, and politics in Latin American social movements theory and research. In: Escobar, A.; Alvarez, S. E. (Ed.). The making of social movements in Latin America: identity, strategy and democracy. Boulder: Westview Press, 1992, p. 1-19.

JELIN, E. Engendering human rights. In: Dore, E. (Ed.). Gender politics in Latin America: debates in theory and practice. New York: Monthly Review Press, 1997, p. 66-83.

MARSHALL, T. H. Citizenship and social class and other essays. Cambridge: Cambridge University Press, 1950.

PAOLI, M. C. Movimentos sociais no Brasil: em busca de um estatuto político. In: Hellmann, M. (Ed.). Movimentos sociais e democracia no Brasil: sem a gente não tem jeito. São Paulo: Marco Zero \& Ildesfes \& Labor, 1995, p. 24-55.

PAOLI, M. C.; Telles, V. da Silva. Social rights: conflicts and negociations in contemporary Brazil. In: Alvarez, S.A.; Dagnino, E.; Escobar, A. (Ed.). Culture of politics: politics of culture. Boulder: Westview Press, 1998, p. 33-63.

SCHAAF, A. van der. Jeito de Mulher Rural; a busca de direitos sociais e da igualdade de gênero no Rio Grande do Sul. Passo Fundo: Editora Universitária de Passo Fundo, 2001.

SCHMUCKLER, B. Las mujeres en la democratización social. In: Estudos Feministas, v. 3, n. 1, 1995, p. 136-152.

SCHWARZER, H. Previdência rural e combate à pobreza no Brasil - Resultados de um estudo de caso no Pará. In: Estudos Sociedade e Agricultura, 14, 2000, p. 72102.

THEIJE, M. de. All that God's is Good: an anthropology of liberationist catholicism in Garanhuns, Brazil. (Thesis Utrecht University) Utrecht: Ceres, 1999.

VOET, R. Feminism and citizenship. London: Sage Publications, 1998. 
Sociologias, Porto Alegre, ano 5, no 10, jul/dez 2003, p. 412-442

\section{Resumo}

Este trabalho trata de processos emancipatórios de mulheres, em especial de pequenas agricultoras no sul do Brasil, no Movimento de Mulheres Trabalhadoras Rurais do Rio Grande do Sul - MMTR-RS. A vida diária das agricultoras nos providencia elementos cruciais para entender a sua ação social, sendo o âmbito em que se produzem os significados culturais. Além disso, o enfoque na vida diária revela o impacto dos contextos históricos, econômicos, religiosos e políticos específicos em que a ação social acontece e nos ajuda a entender como as participantes chegam a problematizar demandas coletivas e a desafiar a arena política.

Palavras-chave: Movimentos sociais, gênero, cidadania, agricultura, Brasil. 